\title{
No Harmful Effect of Dialysis-Induced Hypotension on the Myocardium in Patients Who Have Normal Ejection Fraction and a Negative Exercise Test
}

\author{
Hakan Fotbolcu $^{a}$ Vecih Oduncu ${ }^{d}$ Emre Gürel $^{d}$ Cihan Cevik $^{e}$ Ayhan Erkol ${ }^{d}$ \\ Kıvılcım Özden ${ }^{a}$ Bahtisen Guven ${ }^{b}$ Akın Dayan ${ }^{c}$ Gökçe Şirin ${ }^{a}$ Yelda Basaran ${ }^{d}$ \\ ${ }^{\text {a }}$ Division of Cardiology and b Nephrology and Dialysis Unit, Goztepe Medical Park Hospital, ' Internal Medicine, \\ Haydarpasa Numune Training and Research Hospital, and d Division of Cardiology, Kartal Kosuyolu Heart Education \\ and Research Hospital, Istanbul, Turkey; ${ }^{~}$ Cardiology Division, Texas Heart Institute at St. Luke's Episcopal Hospital, \\ Baylor College of Medicine, Houston, Tex., USA
}

\section{Key Words}

Dialysis-induced hypotension • Biventricular systolic and diastolic functions · Ejection fraction

\begin{abstract}
Background: We investigated the effects of dialysis-induced hypotension (DIH) on the myocardium of patients who have a normal ejection fraction and normal treadmill stress tests. Methods: This study included 26 end-stage renal disease (ESRD) patients with DIH, 30 ESRD patients without DIH (non-DIH), and 30 control subjects. Mitral-myocardial systolic velocity (MSV), the mitral $E^{\prime} / A^{\prime}$ ratio, the left ventricle filling pressure index (E/E' ratio), tricuspid-MSV, and the tricuspid $E^{\prime} / A^{\prime}$ ratio were calculated. Results: Biventricular systolic and diastolic functions were impaired in dialysis patients. The mitral and tricuspid MSV were similar between DIH and nonDIH patients $(8.03 \pm 0.90 \mathrm{~cm} / \mathrm{s}$ vs. $8.31 \pm 1.68 \mathrm{~cm} / \mathrm{s}, \mathrm{p}=$ 0.896 , and $13.27 \pm 2.97 \mathrm{~cm} / \mathrm{s}$ vs. $13.15 \pm 2.37 \mathrm{~cm} / \mathrm{s}, \mathrm{p}=0.980$ ). Mitral and tricuspid $\mathrm{E}^{\prime} / \mathrm{A}^{\prime}$ were similar between DIH and nonDIH patients. $(1.30 \pm 0.53$ vs. $1.16 \pm 0.56, p=0.695$, and 0.70 \pm 0.24 vs. $0.68 \pm 0.33, p=0.976)$. Likewise, the $E / E^{\prime}$ ratio was similar between DIH and non-DIH patients (8.20 \pm 2.83 vs.
\end{abstract}

$8.28 \pm 2.53, p=0.990)$. Conclusion: Although biventricular systolic and diastolic function is impaired in dialysis patients compared to controls, DIH episodes did not have an adverse effect on the myocardial functions.

Copyright $\odot 2012$ S. Karger AG, Basel

\section{Introduction}

Cardiovascular disease is an important cause of mortality in patients undergoing maintenance dialysis, accounting for approximately one half of all deaths [1]. Cardiac failure is common in patients with end-stage renal disease (ESRD) [2]. In addition to direct myocardial depression from a circulating toxin associated with uremia, chronic renal failure has the potential to cause myocardial dysfunction through chronic hypertension [3], premature atherosclerosis due to abnormal carbohydrate and lipid metabolism [4], cardiomyopathy associated with iron overload [5] and volume overload injury due to chronic anemia, hypervolemia, and iatrogenic arteriovenous fistulas $[6,7]$.

\section{KARGER}

Fax +41613061234 E-Mail karger@karger.ch www.karger.com (c) 2012 S. Karger AG, Basel

1420-4096/12/0356-0671\$38.00/0

Accessible online at:

www.karger.com/kbr
Hakan Fotbolcu, MD

Sekercioglu Sokak, Emlakbank Konutlar

154 D blok D:40, Kosuyolu, Kadikoy

TR-34718 Istanbul (Turkey)

E-Mail hakan_fotbolcu@yahoo.com 
Additionally, there is increasing evidence implicating dialysis-induced hypotension (DIH) in the pathophysiology of 'uremic cardiomyopathy'. Intradialytic hypotension increases the risk of myocardial hypoperfusion, leading to segmental ischemia inducing segmental left ventricular (LV) dysfunction [8], a process known as myocardial stunning [9]. Myocardial stunning is cumulative and leads to irreversible LV dysfunction in ischemic heart disease $[10,11]$.

The aim of our study was to investigate the systolic and diastolic function in dialysis patients who have a normal LV ejection fraction and a normal treadmill exercise stress test. Furthermore, we investigated the harmful effects of recurrent DIH episodes on myocardial tissue, and LV systolic and diastolic function.

\section{Methods}

This study included 26 ESRD patients with DIH, 30 ESRD non-DIH patients, and 30 control subjects. Exclusion criteria were: severe morbid obesity (BMI >35); moderate or severe heart valve insufficiency and/or stenosis; congenital heart disease; atrial fibrillation; left bundle branch block; established coronary artery disease (CAD); a history of myocardial infarction, unstable angina pectoris, angiographically proven significant coronary stenosis (more than 50\% luminal stenosis in at least one coronary artery in coronary angiography) or previous revascularization, or an abnormal exercise test; LV ejection fraction $<50 \%$; symptomatic heart failure; poor echocardiographic image quality; stroke; chronic obstructive pulmonary disease, or an orthopedic or musculoskeletal disorder.

Five hundred twenty-two patients with ESRD were evaluated for the determination of DIH during a 6-month run-in period at five hemodialysis (HD) centers. After the 6-month run-in phase and excluding patients based on the enrollment criteria, $26 \mathrm{pa}-$ tients with DIH who had been undergoing 4-hour sessions of HD 3 times a week for $\geq 2$ years were enrolled. We also included 30 age- and sex-matched patients undergoing HD without DIH from this cohort with a similar diabetes mellitus and hypertension prevalence. The control group included 30 patients without renal failure (serum creatinine $<1.2 \mathrm{mg} / \mathrm{dl}$ ). Diabetes was diagnosed according to World Health Organization criteria [12]. Participants were classified as hypertensive if their resting systolic blood pressure (SBP) was $\geq 140 \mathrm{~mm} \mathrm{Hg}$ and/or their diastolic blood pressure (DBP) was $\geq 90 \mathrm{~mm} \mathrm{Hg}$ or if they took antihypertensive medications. Hypertensive patients who were on a medication which may affect the heart rate (verapamil, diltiazem, $\beta$-blockers) quit taking these drugs 1 week before the treadmill stress test. All study patients underwent a thorough clinical, anthropometric, and laboratory examination. Blood samples were obtained the following day after HD before the cardiac stress test and echocardiographic examination. The height and weight of all subjects were measured and the BMI was calculated as weight $(\mathrm{kg})$ divided by height ${ }^{2}(\mathrm{~m})$.

As previously reported, DIH was defined as the presence of one or both of the following conditions on more than 30 occasions among 50 previous sessions of dialysis, [13]: (i) a fall of SBP to less than $90 \mathrm{mmHg}$ during dialysis, and/or (ii) a fall of SBP of more than $25 \%$ from the start of dialysis associated with symptoms related to hypotension, including dizziness, vomiting, nausea, and muscle cramps. BP was measured by trained nursing staff, on the same arm, intermittently at 30-min intervals, with a mercury sphygmomanometer, with the patients seated in multiadjustable chairs. The start and end positions were semi-recumbent. When sudden symptomatic hypotension occurred, BP measurements were repeated in the Trendelenburg position, and hypertonic saline boluses were given as needed. The ultrafiltration rate (\% body weight reduction) during dialysis sessions was adjusted according to the presumed dry weight (assessed as the postdialysis patient's weight when normotensive and free of edema). During the followup period, patients received standard HD using a bicarbonate bath and substituted with cellulose and synthetic membranes. Blood flow rates ranged from 350 to $400 \mathrm{ml} / \mathrm{min}$, the dialysate flow rate was $500 \mathrm{ml} / \mathrm{min}$, and the dialysate temperature was $36^{\circ} \mathrm{C}$. Ultrafiltration was linear and the ultrafiltration rate was adapted to reach the dry weight in the preset dialysis time. No sodium or blood volume profiling was carried out. The dialysate contained $140 \mathrm{mmol} / \mathrm{l} \mathrm{Na}^{+}, 1 \mathrm{mmol} / 1 \mathrm{~K}^{+}, 33 \mathrm{mmol} / 1 \mathrm{HCO}_{3}^{-}, 105$ $\mathrm{mmol} / \mathrm{l} \mathrm{Cl}^{-}, 1.25 \mathrm{mmol} / \mathrm{l} \mathrm{Ca}_{2}{ }^{+}, 0.25 \mathrm{mmol} / \mathrm{Mg}_{2}{ }^{+}$, and $11 \mathrm{mmol} / 1$ glucose. Kt/V was calculated from the Daugirdas formula [14].

\section{Exercise Testing}

The modified Bruce standard protocols used symptom-limited treadmill testing during which leaning on handrails was explicitly not allowed $[15,16]$. With each stage of exercise and recovery (first $3 \mathrm{~min}$ ), data on symptoms, rhythm, heart rate, blood pressure, workload in metabolic equivalents (METs), and ST-segment changes were collected. As per laboratory protocol, exercise could be stopped for marked $(>2.5 \mathrm{~mm})$ ST-segment depression, chest pain, exercise SBP >250 mmHg, and ventricular tachycardia. The exercise ECG was considered positive if there was $0.1 \mathrm{mV}$ or more of J point depression and the ST-segment was flat or downward sloping $0.08 \mathrm{~s}$ after the J point. The treadmill exercise test was interpreted as negative in patients who did not meet the ST depression criteria or who did not develop ST elevation or typical chest pain during the stress test.

\section{Echocardiographic Measurements}

Each patient underwent standard transthoracic two-dimensional echocardiography and exercise testing between $10.00 \mathrm{~h}$ and $16.00 \mathrm{~h}$ on the next day of HD. All echocardiographic assessesments were performed by two operators who were blinded to the clinical and laboratory results of the study group. Vivid 3-dimension echocardiography equipment (GE Vingmed, Horten, Norway) with a $2.5-\mathrm{MHz}$ phased-array transducer was used for each study subject. LV dimension and wall thickness were measured from 2-dimensional guided M-mode echocardiographic tracings at the mid-chordal level on the parasternal long axis view. The Mmode traces were recorded at a speed of $50 \mathrm{~mm} / \mathrm{s}$. Ejection fraction was calculated using the Teicholz formula. The LV mass was estimated using the anatomically validated formula of Devereux et al. [17]. It was indexed for body surface area to estimate the LV mass index.

From the apical four-chamber view, pulsed-wave Doppler recordings of the mitral inflow were obtained with the sample volume placed at the tips of the mitral valve leaflets. The following 
Table 1. Baseline clinical and biochemical parameters of all patients

\begin{tabular}{lcccr}
\hline Variables & DIH $(\mathrm{n}=26)$ & Non-DIH $(\mathrm{n}=30)$ & Control $(\mathrm{n}=30)$ & $\mathrm{p}$ \\
\hline Age, years & $44.15 \pm 12.63$ & $43.70 \pm 11.70$ & $43.37 \pm 13.62$ & 0.973 \\
Males, $\mathrm{n}(\%)$ & $9(34.6)$ & $12(40.0)$ & $17(56.7)$ & 0.215 \\
Diabetes mellitus, n (\%) & $7(26.9)$ & $8(26.7)$ & $7(23.3)$ & 0.940 \\
Hypertension, $\mathrm{n}$ (\%) & $6(23.1)$ & $6(20.0)$ & $7(23.3)$ & 0.943 \\
Baseline SBPa, mm Hg & $116.15 \pm 30.89$ & $142.53 \pm 21.56$ & $131.67 \pm 17.30$ & $<0.001$ \\
Baseline DBPa , mm Hg & $72.69 \pm 17.56$ & $86.50 \pm 16.44$ & $85.03 \pm 9.93$ & 0.001 \\
BMI & $22.33 \pm 4.22$ & $23.32 \pm 4.06$ & $24.92 \pm 3.48$ & 0.011 \\
Hematocrit, \% & $34.92 \pm 1.38$ & $34.73 \pm 1.43$ & $38.06 \pm 3.61$ & $<0.001$ \\
Blood urea, mg/dl & $73.39 \pm 11.31$ & $70.06 \pm 9.97$ & $38.10 \pm 3.88$ & $<0.001$ \\
Serum creatinine, mg/dl & $7.64 \pm 0.74$ & $7.41 \pm 0.68$ & $0.96 \pm 0.09$ & $<0.001$ \\
Potassium, mmol/l & $4.19 \pm 0.29$ & $4.30 \pm 0.35$ & $4.14 \pm 0.28$ & 0.139 \\
Calcium, mg/dl & $9.06 \pm 0.37$ & $9.17 \pm 0.41$ & $9.16 \pm 0.32$ & 0.560 \\
Phosphorus, mg/dl & $5.49 \pm 0.39$ & $5.64 \pm 0.57$ & $3.73 \pm 0.19$ & $<0.001$ \\
Albumin, g/dl & $3.96 \pm 0.25$ & $4.01 \pm 0.23$ & $4.07 \pm 0.25$ & 0.205 \\
Dialysis duration, months & $73.12 \pm 41.60$ & $72.37 \pm 59.02$ & - & 0.392 \\
Mean Kt/V urea value & $1.32 \pm 0.09$ & $1.33 \pm 0.07$ & - & 0.462 \\
Weight reduction, \% & $3.21 \pm 0.44$ & $3.08 \pm 0.52$ & - & 0.317 \\
\hline
\end{tabular}

${ }^{a}$ Post hoc analysis of the groups is given in Results.

parameters were measured by pulsed-wave Doppler: peak velocities of early (E) and late diastolic filling (A), and deceleration time. The ratio of early diastolic to late diastolic mitral inflow velocities was calculated (E/A). All Doppler signals were recorded with a chart recorder set at $100 \mathrm{~mm} / \mathrm{s}$. The averages of 3 cycles were used.

The TDI program was set to pulsed-wave Doppler mode. Filters were set to exclude high frequency signals. Gains were minimized to allow a clear tissue signal with minimal background noise. The TDI of the diastolic and systolic velocities was obtained from the apical 4-chamber view. A 1.5-mm sample volume was placed at the lateral corner of the mitral and tricuspid annulus. Analysis was performed for early $\left(\mathrm{E}^{\prime}\right)$ and late diastolic velocity $\left(\mathrm{A}^{\prime}\right)$ and myocardial systolic velocity (MSV) and the $\mathrm{E}^{\prime} / \mathrm{A}^{\prime}$ ratio.

LV systolic function was evaluated with mitral MSV, and diastolic function was evaluated with mitral inflow E/A ratio and mitral $E^{\prime} / A^{\prime}$ ratio parameters. In addition, E/E' was calculated as an indicator of the left ventricle filling pressure. Right ventricular systolic function was assessed with tricuspid MSV. Right ventricular diastolic function was evaluated with tricuspid $\mathrm{E}^{\prime} / \mathrm{A}^{\prime}$ since this parameter is relatively less affected by the preload condition [18].

\section{Statistical Analysis}

All statistical analyses were performed using SPSS 11.5 (SPSS Inc., Chicago, Ill., USA). Data are presented as means \pm SD for each group of measurements. The frequency distribution of categorical variables was tested using a $2 \times 2$ contingency table. Continuous variables of two groups were compared using Student's t test, and the Mann-Whitney U test was used when a nonnormal distrubution was present. ANOVA and Kruskall-Wallis tests were used during the comparison of three groups with each other depending on the normal distrubution of the data. For the post hoc test, we used the Tukey HSD (honestly significant differ- ence) test for the variables that were significant in ANOVA, and the Mann-Whitney $U$ test for the variables that were significant in the Kruskall-Wallis test. Correlations between the variables were tested by Pearson's correlation analysis. In all statistical analyses, two-tailed $\mathrm{p}$ values $<0.05$ were considered statistically significant.

\section{Results}

Fifty-six HD patients (mean age $43.9 \pm 11.8$ years) and 30 controls (mean age $43.4 \pm 13.6$ years) were included in this study. Baseline clinical and biochemical parameters of the study population are presented in table 1. All groups were similar in terms of age, gender, prevalence of diabetes and hypertension, antihypertensive medication profile, serum potassium, serum calcium, and serum albumin levels. The control group had increased BMI compared to the patients on HD $(\mathrm{p}=0.011)$. The DIH group had lower baseline SBP compared to non-DIH patients and controls $(116.15 \pm 30.89 \mathrm{~mm}$ Hg vs. $142.53 \pm 21.56$ $\mathrm{mm} \mathrm{Hg}, \mathrm{p}<0.001$, and $116.15 \pm 30.89 \mathrm{~mm} \mathrm{Hg}$ vs. 131.67 $\pm 17.30 \mathrm{~mm} \mathrm{Hg}, \mathrm{p}=0.042$ ). The baseline SBP of non-DIH patients and the control group were similar (142.53 \pm $21.56 \mathrm{~mm} \mathrm{Hg}$ vs. $131.67 \pm 17.30 \mathrm{~mm} \mathrm{Hg}, \mathrm{p}=0.180)$. The DIH group had lower baseline DBP compared to the nonDIH and control patients (72.69 $\pm 17.56 \mathrm{~mm} \mathrm{Hg}$ vs. 86.50 $\pm 16.44 \mathrm{~mm} \mathrm{Hg}, \mathrm{p}=0.002$, and $72.69 \pm 17.56 \mathrm{~mm} \mathrm{Hg}$ 




Fig. 1. Correlations between baseline SBP and the LV mass of dialysis patients.

Table 2. Structural echocardiographic parameters of all patients

\begin{tabular}{lcccc}
\hline $\begin{array}{l}\text { Echocardio- } \\
\text { graphic } \\
\text { parameters }\end{array}$ & DIH & Non-DIH & Control & $\mathrm{p}$ \\
\hline IVS-D, cm & $1.05 \pm 0.15$ & $1.06 \pm 0.12$ & $0.97 \pm 0.17$ & 0.082 \\
PW-D, cm & $0.96 \pm 0.14$ & $0.95 \pm 0.10$ & $0.86 \pm 0.16$ & 0.012 \\
LVEDD, cm & $4.74 \pm 0.41$ & $4.72 \pm 0.27$ & $4.59 \pm 0.36$ & 0.240 \\
LVESD, cm & $3.10 \pm 0.44$ & $3.04 \pm 0.32$ & $2.90 \pm 0.39$ & 0.135 \\
LVEF, \% & $63.9 \pm 4.9$ & $64.6 \pm 2.5$ & $63.9 \pm 3.4$ & 0.703 \\
RVEDD, cm & $3,23 \pm 0.34$ & $3.17 \pm 0.28$ & $3,12 \pm 0.34$ & 0.460 \\
LV mass ${ }^{a}, g$ & $169.2 \pm 41.1$ & $169.3 \pm 38.2$ & $138.6 \pm 47.8$ & 0.009 \\
LV mass index & & & & \\
$\quad$ g/m ${ }^{3}$ & $108.7 \pm 27.6$ & $104.0 \pm 27.6$ & $71.6 \pm 21.2$ & $<0.001$ \\
\end{tabular}

IVS-D = Interventricular septum diastolic thickness; PW-D = posterior wall diastolic thickness; LVEDD = left ventricul enddiastolic diameter; LVESD = left ventricle end-systolic diameter; $\mathrm{LVEF}=$ left ventricular ejection fraction; RVEDD = right ventricle end-diastolic diameter. ${ }^{\text {a }}$ Post hoc analysis of the groups is given in Results.

vs. $85.03 \pm 9.93 \mathrm{~mm} \mathrm{Hg}, \mathrm{p}=0.008$ ). Baseline DBP were similar between the non-DIH and control groups (86.50 $\pm 16.44 \mathrm{~mm} \mathrm{Hg}$ vs. $85.03 \pm 9.93 \mathrm{~mm} \mathrm{Hg}, \mathrm{p}=0.923)$.

The structural echocardiographic parameters of all patients are presented in table 2 . Dialysis patients had increased LV wall thickness, LV mass, and mass index compared to the control group. There was no difference be- tween the DIH and non-DIH groups in terms of LV mass and mass index $(\mathrm{p}>0.05)$. The LV ejection fraction was similar in the three groups $(\mathrm{p}=0.703)$.

The Doppler measurements of all patients are presented in table 3. The DIH and non-DIH groups had reduced mitral myocardial systolic velocities compared to the controls $(8.03 \pm 1.90 \mathrm{~cm} / \mathrm{s}$ vs. $10.78 \pm 3.21 \mathrm{~cm} / \mathrm{s}, \mathrm{p}<$ 0.001 , and $8.31 \pm 1.68 \mathrm{~cm} / \mathrm{s}$ vs. $10.78 \pm 3.21 \mathrm{~cm} / \mathrm{s}, \mathrm{p}<$ 0.001). The mitral MSV values of the DIH and non-DIH subgroups were statistically similar $(8.03 \pm 1.90 \mathrm{~cm} / \mathrm{s}$ vs. $8.31 \pm 1.68 \mathrm{~cm} / \mathrm{s}, \mathrm{p}=0.896)$. The non-DIH group had a reduced mitral $\mathrm{E}^{\prime} / \mathrm{A}^{\prime}$ ratio compared to the controls (1.16 \pm 0.56 vs. $1.70 \pm 0.81, \mathrm{p}=0.005)$. The mitral $\mathrm{E}^{\prime} / \mathrm{A}^{\prime}$ ratio values of the DIH versus non-DIH and DIH versus control subgroups were statistically similar $(1.30 \pm 0.53$ vs. $1.16 \pm 0.56, \mathrm{p}=0.695$, and $1.30 \pm 0.53$ vs. $1.70 \pm 0.81$, $\mathrm{p}=0.062$ ). The DIH and non-DIH groups had reduced mitral inflow $\mathrm{E} / \mathrm{A}$ ratios compared to the controls $(0.88$ \pm 0.31 vs. $1.21 \pm 0.37, \mathrm{p}=0.001$, and $0.91 \pm 0.26$ vs. 1.21 $\pm 0.37, \mathrm{p}=0.002$ ). The mitral inflow $\mathrm{E} / \mathrm{A}$ ratio values of the DIH and non-DIH subgroups were statistically simi$\operatorname{lar}(0.88 \pm 0.31$ vs. $0.91 \pm 0.26, \mathrm{p}=0.927)$. The DIH and non-DIH groups had increased $\mathrm{E} / \mathrm{E}^{\prime}$ ratios compared to the controls $(8.20 \pm 2.83$ vs.6.21 $\pm 1.87, \mathrm{p}=0.009$, and $8.28 \pm 2.53$ vs. $6.21 \pm 1.87, \mathrm{p}=0.004)$. The $\mathrm{E} / \mathrm{E}^{\prime}$ ratio values of the DIH and non-DIH subgroups were statistically similar $(8.20 \pm 2.83$ vs. $8.28 \pm 2.53, \mathrm{p}=0.990)$.

ANOVA analysis demonstrated that tricuspid MSV values were statistically reduced in patients on dialysis $(p=0.042)$. However, post hoc analysis did not demonstrate a significant difference between each group ( $p>$ $0.05)$. The DIH and non-DIH groups had reduced tricuspid $\mathrm{E}^{\prime} / \mathrm{A}^{\prime}$ ratios compared to the controls $(0.70 \pm 0.24 \mathrm{vs}$. $1.08 \pm 0.53, \mathrm{p}=0.002$, and $0.68 \pm 0.33$ vs. $1.08 \pm 0.53$, $\mathrm{p}=0.001)$. The tricuspid $\mathrm{E}^{\prime} / \mathrm{A}^{\prime}$ ratio values of the $\mathrm{DIH}$ and non-DIH subgroups were statistically similar $(0.70 \pm 0.24$ vs. $0.68 \pm 0.33, \mathrm{p}=0.976$ ). Pearson's correlation analysis including dialysis duration, baseline SBP, baseline DBP, BMI, hematocrit levels, and echocardiographic parameters was performed on the dialysis patients. This analysis demonstrated a moderate strength correlation between the baseline SBP and LV mass $(\mathrm{r}=0.45, \mathrm{p}<0.001)$ (fig. 1$)$.

\section{Discussion}

In our study, we found that biventricular systolic and diastolic functions were impaired in dialysis patients who were free from CAD demonstrated by a negative treadmill stress test and echocardiography. Furthermore, we 
Table 3. Doppler measurements of all patients

\begin{tabular}{|c|c|c|c|c|}
\hline & $\mathrm{DIH}$ & Non-DIH & Control & $\mathrm{p}$ \\
\hline \multicolumn{5}{|l|}{ Mitral inflow } \\
\hline Peak E, cm/s & $71.92 \pm 18.33$ & $80.00 \pm 19.29$ & $76.97 \pm 16.22$ & 0.240 \\
\hline Peak A, cm/s & $84.62 \pm 20.82$ & $89.33 \pm 18.18$ & $66.27 \pm 14.66$ & $<0.001$ \\
\hline $\mathrm{E} / \mathrm{A}$ ratio $^{\mathrm{a}}$ & $0.88 \pm 0.31$ & $0.91 \pm 0.26$ & $1.21 \pm 0.37$ & $<0.001$ \\
\hline $\mathrm{DT}, \mathrm{ms}$ & $224.5 \pm 31.8$ & $234.5 \pm 34.9$ & $190.8 \pm 32.2$ & $<0.001$ \\
\hline \multicolumn{5}{|l|}{ Lateral mitral annulus } \\
\hline Myocardial systolic velocity ${ }^{\mathrm{a}}, \mathrm{cm} / \mathrm{s}$ & $8.03 \pm 0.90$ & $8.31 \pm 1.68$ & $10.78 \pm 3.21$ & $<0.001$ \\
\hline $\mathrm{E}^{\prime}$ peak velocity, $\mathrm{cm} / \mathrm{s}$ & $9.19 \pm 2.55$ & $10.31 \pm 3.15$ & $12.94 \pm 4.36$ & $<0.001$ \\
\hline $\mathrm{A}^{\prime}$ peak velocity, $\mathrm{cm} / \mathrm{s}$ & $7.60 \pm 2.04$ & $9.73 \pm 2.41$ & $8.11 \pm 1.96$ & 0.001 \\
\hline $\mathrm{E}^{\prime} / \mathrm{A}^{\prime}$ ratio $^{\mathrm{a}}$ & $1.30 \pm 0.53$ & $1.16 \pm 0.56$ & $1.70 \pm 0.81$ & 0.005 \\
\hline \multicolumn{5}{|l|}{ Lateral tricuspid annulus } \\
\hline Myocardial systolic velocity ${ }^{\mathrm{a}}, \mathrm{cm} / \mathrm{s}$ & $13.27 \pm 2.97$ & $13.15 \pm 2.37$ & $14.58 \pm 1.67$ & 0.042 \\
\hline $\mathrm{E}^{\prime}$ peak velocity, $\mathrm{cm} / \mathrm{s}$ & $9.84 \pm 3.11$ & $9.75 \pm 2.86$ & $12.41 \pm 3.32$ & 0.002 \\
\hline $\mathrm{A}^{\prime}$ peak velocity, $\mathrm{cm} / \mathrm{s}$ & $14.34 \pm 3.26$ & $15.92 \pm 5.07$ & $12.44 \pm 3.22$ & 0.005 \\
\hline $\mathrm{E}^{\prime} / \mathrm{A}^{\prime}$ ratio $^{\mathrm{a}}$ & $0.70 \pm 0.24$ & $0.68 \pm 0.33$ & $1.08 \pm 0.53$ & $<0.001$ \\
\hline \multicolumn{5}{|l|}{ LV filling pressure } \\
\hline $\mathrm{E} / \mathrm{E}^{\prime}$ ratio $^{\mathrm{a}}$ & $8.20 \pm 2.83$ & $8.28 \pm 2.53$ & $6.21 \pm 1.87$ & 0.002 \\
\hline
\end{tabular}

DT $=$ Deceleration time. ${ }^{\text {a }}$ Post hoc analysis of the groups is given in Results.

found that DIH episodes were not associated with adverse effects on the myocardium among this specific dialysis patient population.

Uremia increases the myocardial interstitial ground substance by mechanisms independent of hypertension [19]. The hyperparathyroid state and altered vitamin D status found in chronic renal failure contribute to the cardiovascular pathology (fibrosis, cardiomyopathy, myocardial hypertrophy, myocardial ischemia, uremic glucose intolerance, dyslipidemia, hypertension, atherosclerosis, and vascular and cardiac calcifications) and also to the excess mortality from cardiovascular causes [20]. A high prevalence of arteriosclerosis and remodeling of large arteries causes a reduction in arterial compliance, thereby leading to increased SBP, increased pulse pressure, LV hypertrophy (LVH), and decreased coronary perfusion [21]. HD treatment may affect cardiac functions by itself. Increased myocardial calcium content is strongly associated with myocardial dysfunction in patients undergoing dialysis [22]. Similar to previous studies, the dialysis patients had impaired biventricular systolic and diastolic function compared to the control group. Our findings contribute significantly to the literature, especially after excluding the CAD of these patients by echocardiography and exercise stress tests. In addition, the dialysis patients had increased LV mass and LVMI compared to the controls. Patients with DIH had reduced baseline SBP and DBP levels compared to the non-DIH group; however, both groups had similar LV mass and LVMI levels. These findings represent a multifactorial etiology for the development of LVH in dialysis patients, especially after considering the significant correlation between LV mass and baseline SBP in the correlation analysis.

HD patients are particularly susceptible to myocardial ischemia. In addition to the high prevalence of coronary artery atheroma [23], diabetic dialysis patients have been shown to have a reduced coronary flow reserve (CFR) in the absence of coronary vessel stenoses [24]. CFR determines the ability to increase blood flow to the myocardium during increased demand, and there is preliminary evidence that the same reduction in CFR is also seen in nondiabetic dialysis patients [25]. In part this may be caused by $\mathrm{LVH}$, present in $74 \%$ of patients on dialysis [26], which reduces the CFR and is associated with a myocytecapillary mismatch [27]. Increased peripheral artery stiffness is also recognized to have an adverse effect on myocardial perfusion and reduces the ischemic threshold [28]; therefore, $\mathrm{LVH}$ in tandem with increased vascular stiffness may lead to a propensity to reduced subendocardial blood flow [29]. In addition, dysregulation of blood pressure control due to abnormal baroreflex sensitivity [30] and vasoregulatory failure [31] increases the risk of myocardial hypoperfusion. 
DIH is an important complication in HD patients. It occurs in one third of patients on dialysis. This condition is also associated with increased morbidity and decreased overall quality of life [32]. The mechanism of DIH has been explained as the imbalance between a decreased plasma volume during HD and counter-regulatory cardiovascular and neurohormonal mechanisms [33, 34]. These sudden changes in blood pressure may provoke subendocardial ischemia/necrosis or myocardial stunning. The average dialysis period of our study patients was 6 years and CAD was excluded by noninvasive tests. We found that DIH episodes were not associated with an adverse impact on the myocardium among this specific dialysis patient population. Selby et al. $[9,10]$ reported that a significant number of new LV regional wall motion abnormalities occurred during standard dialysis. The same studies showed that improving the mean blood pressure and reducing DIH with both biofeedback dialysis and cool temperature dialysis was associated with a significant reduction in the number of new regional wall motion abnormalities. The incidence of diabetes mellitus was greater in these studies compared to our patients, and the patients were more heterogenous in terms of ischemic heart disease in the study by Selby et al. [9, 10]. Owen et al. [35] demonstrated the impaired myocardial contractile reserve in patients with DIH by a dobutamine-atropin stress test in their small study. The authors did not observe any ischemic ECG changes or angina suggesting epicardial CAD during this study. The impaired contractile reserve in this study may originate from the insufficient response to the pharmacological agents at the myocardial receptor level since the tissue Doppler MSV values of our dialysis patients were all similar. Our study makes a significant contribution to the literature with its large number of study patients and by excluding CAD with the exercise stress test. The dialysis patients in our study had mild $\mathrm{LVH}$ and the prevalence of diabetes was low (26\%). These findings indicate that the CFR values might have been preserved in our study patients. Similarly, the DIH and non-DIH groups had impaired systolic and diastolic functions compared to controls; however, these were similar to each other. This result suggests that myocardial functions play a minor role in the development of DIH for this specific population of patients who have preserved ejection fraction.

\section{Limitations of the Study}

We excluded the presence of epicardial stenotic lesions with an exercise stress test in our study group. We did not perform a coronary arteriogram since there was no clinical indication to justify this invasive procedure. Longterm randomized clinical trials on patients with or without critical epicardial CAD are needed to demonstrate the impact of DIH episodes on the myocardial functions. Similarly, randomized follow-up studies according to CFR values are needed in patients in whom CFR was quantitatively measured.

In conclusion, the biventricular systolic and diastolic functions were impaired compared to controls in dialysis patients who had normal LV ejection fraction and negative stress test. We did not observe any adverse effect of dialysis-induced hypotensive episodes on myocardial functions in the subgroup of dialysis patients.

\section{Acknowledgements}

The authors are grateful for the exellent nursing support from Yasemin Bozalp and Yeliz Ozkan Cetin during the treadmill cardiac stress tests and nursing care from Serpil Gunduz during the dialysis of the study patients. We appreciate the excellent secretarial assistance of Ayten Bolut during the preparation of this paper.

\section{Disclosure Statement}

The authors declare that there are no conflicts of interest.

\section{References}

1 United States Renal Data System 2006 Annual Data Report: Atlas of chronic kidney disease and end-stage renal disease in the United States. Morbidity and mortality. Am J Kidney Dis 2007;49(suppl 1):S1-S146.

2 Capelli JP, Kasparian H: Cardiac work demands and left ventricular function in endstage renal disease. Ann Intern Med 1977;86: 261-267.
3 ScharfS, Wexler J, Longnecker RE, et al: Cardiovascular disease in patients on chronic hemodialytic therapy. Prog Cardiovasc Dis 1980;22:343-356.

4 Lindner A, Charra B, Sherrard DJ, et al: Accelerated atherosclerosis in prolonged maintenance hemodialysis. N Eng J Med 1974; 290:697-701.

5 Ali M, Fayemi O, Rigolosi R, et al: Hemosiderosis in hemodialysis patients. An autopsy study of 50 cases. JAMA 1980;244:343-345.
6 Riley SM, Blackstone EJ, Sterling WA, et al: Echocardiographic assessment of cardiac performance in patients with arteriovenous fistulas. Surg Gynecol Obstet 1978;146:203208.

7 Pinsky WW, Lewis RM, Hartley CJ, et al: Permanent changes of ventricular contractility and compliance in chronic volume overload. Am J Physiol 1979;237:H575$\mathrm{H} 583$.

Fotbolcu/Oduncu/Gürel/Cevik/Erkol/ Özden/Guven/Dayan/Şirin/Basaran 
8 McIntyre CW, Burton JO, Selby NM, et al: Hemodialysis-induced cardiac dysfunction is associated with an acute reduction in global and segmental myocardial blood flow. Clin J Am Soc Nephrol 2008;3:19-26.

$\checkmark 9$ Selby NM, Burton JO, Chesterton LJ, et al: Dialysis induced regional left ventricular dysfuntion is ameliorated by cooling dialysate. Clin J Am Soc Nephrol 2006;1:12161225.

10 Selby NM, Lambie SH, Camici PG, et al: Occurrence of regional left ventricular dysfuntion in patients undergoing standart and biofeedback dialysis. Am J Kidney Dis 2006;47: 830-841.

-11 Singh N, Langer A, Freeman MR, et al: Myocardial alterations during hemodialysis: insights from new noninvasive technology. Am J Nephrol 1994;14:173-181.

12 World Health Organization: Diabetes mellitus: a report of a WHO Study Group. WHO publication 727. Geneva, WHO, 1985.

13 Sato M, Horigome I, Chiba S, et al: Autonomic insufficiency as a factor contributing to dialysis-induced hypotension. Nephrol Dial Transplant 2001;16:1657-1662.

14 Daugirdas JT: Second generation logarithmic estimates of single-pool variable volume $\mathrm{Kt} / \mathrm{V}$ : an analysis of error. J Am Soc Nephrol 1993;4:1205-1213.

-15 Doan AE, Peterson DR, Blackmon JR, et al: Myocardial ischemia after maximal exercise in healthy men. Am Heart J 1965;69:11-21.

$\checkmark 16$ Fletcher GF, Froelicher VF, Hartley LH, et al: Exercise standards: a statement for health professionals from the American Heart Association. Circulation 1990;82:2286-2322. $\checkmark 17$ Devereux RB, Alonso DR, Lutas EM, et al: Echocardiographic assessment of the left ventricular hypertrophy: comparison necropsy findings. Am J Cardiol 1986;57:450458.

18 Arinc H, Gunduz H, Tamer A, et al: Use of tissue Doppler to assess right ventricle function in hemodialysis patients. Am J Nephrol 2005;25:256-261.

19 Mall G, Rambausek M, Neumeister A, et al Myocardial interstitial fibrosis in experimental uremia-implications for cardiac compliance. Kidney Int 1988;33:804-811.

20 Rostand SG, Drueke TB: Parathyroid hormone, vitamin $\mathrm{D}$, and cardiovascular disease in chronic renal failure. Kidney Int 1999;56: 383-392.

21 London GM, Marchais SJ, Guerin AP, et al Arterial structure and function in end-stage renal disease. Nephrol Dial Transplant 2002; 17:1713-1724.

22 Rostand SG, Sanders C, Kirk KA, et al: Myocardial calcification and cardiac dysfunction in chronic renal failure. Am J Med 1988;85: 651-657.

23 Cheung AK, Sarnak MJ, Yan G, et al: Cardiac diseases in maintenance hemodialysis patients: results of the HEMO Study. Kidney Int 2004;65:2380-2389.

24 Ragosta M, Samady H, Isaacs RB, et al: Coronary flow reserve abnormalities in patients with diabetes mellitus who have end-stage renal disease and normal epicardial coronary arteries. Am Heart J 2004;147:10171023.

25 Tok D, Gullu H, Erdogan D, et al: Impaired coronary flow reserve in hemodialysis patients: a transthoracic Doppler echocardiographic study. Nephron Clin Pract 2005; 101:c200-c206.
26 Foley RN, Parfrey PS, Harnett JD, et al: Clinical and echocardiographic disease in patients starting end-stage renal disease therapy. Kidney Int 1995;47:186-192.

27 Parfrey PS: Pathogenesis of cardiac disease in dialysis patients. Semin Dial 1999;12:6268.

28 Kingwell BA, Waddell TK, Medley TL, et al: Large artery stiffness predicts ischemic threshold in patients with coronary artery disease. J Am Coll Cardiol 2002;40:773-779.

29 London GM, Guerin AP, Marchais SJ, et al: Cardiac and arterial interactions in endstage renal disease. Kidney Int 1996;50:600608 .

30 Robinson TG, Carr SJ: Cardiovascular autonomic dysfunction in uremia. Kidney Int 2002;62:1921-1932.

31 Stewart GA, Mark PB, Johnston N, et al: Determinants of hypertension and left ventricular function in end-stage renal failure: a pilot study using cardiovascular magnetic resonance imaging. Clin Physiol Funct Imaging 2004;24:387-393

>32 Henrich WL: Hemodynamic instability during hemodialysis. Kidney Int 1986;30:605612 .

33 Daugirdas JT: Pathophysiology of dialysis hypotension: an update. Am J Kidney Dis 2001;38(suppl 4):S11-S17.

34 Fotbolcu H, Duman D, Ecder SA, et al: Attenuated cardiovascular response to sympathetic system activation during exercise in patients with dialysis induced hypotension. Am J Nephrol 2011;33:491-498.

35 Owen PJ, Priestman WS, Sigrist MK, et al: Myocardial contractile function and intradialytic hypotension. Hemodial Int 2009; 13 : 293-300 